\title{
COST-EFFECTIVENESS ANALYSIS OF INSULIN REGIMEN ON TYPE 2 DIABETES MELLITUS OUTPATIENT IN DENPASAR MUNICIPALITY
}

\section{LUH PUTU FEBRYANA LARASANTY*, MADE ARY SARASMITA, I GUSTI NGURAH AGUNG DEWANTARA PUTRA}

Department of Pharmacy, Faculty of Mathematics and Basic Science, Udayana University, Bali, Indonesia. Email: febryana@unud.ac.id

Received: 25 March 2017, Revised and Accepted: 28 September 2017

\section{ABSTRACT}

Objective: Insulin is one of the antidiabetic agents that available for the treatment of type 2 diabetes mellitus (T2DM) patients. Insulin has several types of formulation, with its cost and effectiveness. The aim of this study was to compare the cost-effectiveness of insulin regimen in the therapy management of T2DM outpatient.

Methods: Cost-effectiveness analysis has been done by calculating the average cost-effectiveness ratio (ACER) and incremental cost-effectiveness ratio (ICER) of each insulin regimens. Effectiveness was measured by improvement of fasting blood glucose, postprandial blood glucose, and HbA1c value. The total cost of insulin regimen was calculated from direct medical cost, direct nonmedical cost, and indirect nonmedical cost.

Results: Overall, 42 patients meet the inclusion criteria were included this study. There were four insulin regimens compared, namely, insulin detemir, premixed insulin aspart, insulin aspart, and a combination of insulin aspart + insulin glargine. The combination of insulin aspart + insulin glargine provides pre-eminent therapy effectiveness (58.82\%), whereas insulin detemir regimen has the lowest total cost (102.62 USD). Calculation of ACER showed that insulin aspart has the lowest ACER value, in an amount of 1.91 USD per percentage of effectiveness. Based on ICER value, insulin aspart was the better choice compared to the combination of insulin aspart + insulin glargine ( 0.18 USD vs. 0.82 USD).

Conclusion: The variation of therapeutic effectiveness and total cost was observed in the management of T2DM outpatient. Based on ACER and ICER value, insulin aspart was the most cost-effective insulin compared to another insulin regimen on the study.

Keywords: Average cost-effectiveness ratio, Cost-effectiveness analysis, Incremental cost-effectiveness ratio, Insulin, Type 2 diabetes mellitus.

(C) 2018 The Authors. Published by Innovare Academic Sciences Pvt Ltd. This is an open access article under the CC BY license (http://creativecommons. org/licenses/by/4. 0/) DOI: http://dx.doi.org/10.22159/ajpcr.2018.v11i1.18695

\section{INTRODUCTION}

Type 2 diabetes mellitus (T2DM) is one of the degenerative diseases that become a risk factor for cardiovascular diseases such as stroke, ischemic heart disease, and chronic kidney diseases [1]. This disease is a chronic illness that requires high treatment costs. In 2012, medical expenses spent for the treatment of T2DM patients in the United States reached 245 billion dollars. Patient with T2DM paid medical costs 2.3 times higher than for those without diabetes. Most of medical costs incurred by T2DM patients used to direct medical costs associated with patient treatment, including antidiabetic drug supply $[2,3]$.

Insulin is one of antidiabetic agent which plays an important role for the treatment of T2DM patients. Insulin analogs were developed to mimic the basal and bolus components of physiologic insulin secretion $[4,5]$. There are several types of insulin formulations such as rapid-acting insulin, short-acting insulin, long-acting insulin, and premixed insulin formulation [6]. The differences of formulations produce a different price for each unit of insulin result in a difference in total costs for each treatment regimen [7-9]. We analyzed a comparison between cost and effectiveness the used of insulin therapy regimens in management of T2DM outpatient in Denpasar Municipality

\section{METHODS}

\section{Study design}

This study is a pharmacoeconomic research of insulin regimen usage in T2DM outpatient at the two general hospitals in Denpasar municipality, Bali, Indonesia. Type of this pharmacoeconomic study was costeffectiveness analysis with average cost-effectiveness ratio (ACER) and incremental cost-effectiveness ratio (ICER) calculation. ACER was obtained by dividing the total cost by the percentage of therapeutic effectiveness. ICER calculated by dividing differences of the total cost to the differences in the effectiveness of a therapy regimen [10-12].

\section{Inclusion and exclusion criteria}

The patient included in this study had uncontrolled blood glucose level, received insulin regimen without oral anti-diabetes drugs, live in Denpasar municipality, and willing to participate in research. Patient with comorbid diseases, pregnancy, use oral contraception, or another drug that can affect blood glucose level were excluded from participating in this study. All patients who met the assigned criteria were included as research subjects.

\section{Data collection}

Clinical effectiveness of insulin regimen was measured by fasting blood glucose (FBG) level, postprandial blood glucose (PBG) level, and glycated hemoglobin (HbA1c) value. Every patient had been followed up for three consecutive months. FBG and PBG parameters measured at baseline (initial of study) and every month during the study. Glycated hemoglobin measured at the baseline and the $3^{\text {rd }}$ month of study. Examination conducted in the clinical laboratory of each hospital. Data of effectiveness parameters were taken from laboratory results sheet at patient medical records.

The total cost of insulin regimen calculated from direct medical cost (doctor service fee, insulin and its equipment costs, and cost of laboratory examination), direct nonmedical cost (administration fees and transportation), and indirect nonmedical cost (loss of salary/ earnings for absent from work). Data for doctor service charge, price of each type of insulin and its equipment costs, the cost of laboratory examination, and administration fees taken from administration billing and pharmacy medical report. Transportation cost calculated from round trip mileage from patient's home to the hospital multiplied by 
transportation operating cost in Denpasar municipality. Loss of salary/ earnings for absent from work was obtained from patient's work history.

\section{Data analysis}

Clinical effectiveness parameters (FBG, PBG, and HbA1c) are presented as the mean \pm standard deviation (SD). Change in the outcome values (baseline to 3-month follow-up result) is calculated as percentages (\%) reduction from baseline data. Statistical analysis of clinical parameters by analysis of variance followed with LSD test. The cost for each clinical outcome derived from a total cost of insulin regimen divided by the total reduction changes of each parameter. Total clinical effectiveness was calculated based on the number of patients in each regimen group which meet the clinical target (FBG $80-130 \mathrm{mg} / \mathrm{dL}, \mathrm{PBG}<180 \mathrm{mg} / \mathrm{dL}$, and $\mathrm{HbA} 1 \mathrm{c}<7 \%$ [13] divided by the total patient in each regimen group. Total clinical effectiveness is presented in percentage (\%) effectiveness. ACER and ICER calculated based on ACER and ICER equation from the World Health Organization guide to cost-effectiveness analysis (CEA) [12].

\section{Ethical approval}

This study has received ethical approval from the Ethics Committee of Sanglah General Hospital number 1278/UN.14.2/Litbang/2016. Informed consent was obtained from all patients who participated in this study.

\section{RESULT}

\section{Patient disposition}

A total of 184 T2DM patient records were available from the internal medicine outpatient department. 43 patients were meet inclusion and exclusion criteria and were included in this study. From 43 patients, one patient was excluded from the entire analysis because lost to follow-up at monthly check up, remaining 42 patients as the study subjects. Those patients then followed up for 3 months to assess insulin effectiveness (Fig. 1).

\section{Clinical effectiveness of insulin regimen}

There were four types of insulin regimen that mostly used by T2DM outpatient in general hospital at Denpasar municipality. They were insulin aspart (NovoRapid®), insulin detemir (Levemir $®$ ), premixed insulin aspart 30\% and protamine crystallized insulin aspart 70\% (NovoMix $®$ ), and a combination of insulin aspart (NovoRapid®) plus insulin glargine (Lantus ${ }^{\circledR}$ ). Insulin regimen outcomes from baseline to 3-month follow-up period are shown in Table 1. Based on FBG, PBG and $\mathrm{HbA} 1 \mathrm{c}$ measurements from baseline to the 3rd-month follow-up, showed that the used of insulin therapy could provide a reduction in the patient's blood glucose level. There is no significant difference ( $p>0.05)$ in the outcome at the $3^{\text {rd }}$ month of follow-up for the FBG, PBG, and $\mathrm{HbA1c}$ between each regimen group.

The highest total reduction of clinical outcome parameters obtained in insulin aspart regimen group with the total reduction in FBG was $50.65 \%$, PBG was $37.24 \%$, and HbA1c was $35.90 \%$. A statistically significant differences $(\mathrm{p}<0.01)$ in a total reduction of FBG and HbA1c

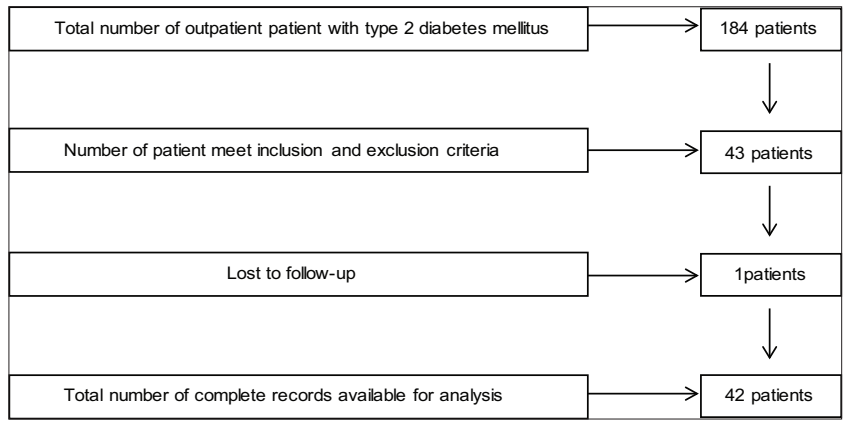

Fig. 1: Patient disposition were observed between each treatment group. While for PBG reduction, the significant differences $(\mathrm{p}<0.05)$ only observed in insulin aspart regimen versus premixed insulin regimen and combination insulin aspart + insulin glargine regimen versus premixed insulin regimen.

Total \% effectiveness of insulin regimen is summarized in Table 2 . The combination of insulin aspart + insulin glargine gives the highest total effectiveness (58.82\%) compared to the other insulin regimen. Insulin aspart regimen which gives a highest total reduction on each parameter was at the second position with overall achievement on total effectiveness as much as $57.14 \%$

\section{Cost-effectiveness measurement}

Differences between clinical outcome of each insulin regimen and differences of the total cost result in different average cost for each clinical parameter. Calculation of the average cost for each reduction of clinical outcomes can be seen in Table 2. Insulin aspart has the lowest average cost for each clinical parameter reduction, whereas premixed insulin was the regimen with highest average cost. The average cost of every $\mathrm{mg} / \mathrm{dL}$ reduction of FBG was 0.86 USD for insulin aspart versus 10.62 USD for premixed insulin. For PBG, an average cost of every $\mathrm{mg} / \mathrm{dL}$ reduction was 0.99 USD for insulin aspart versus 19.24 USD for premixed insulin. Every percentage (\%) reduction in HbA1c of insulin aspart required an average cost of 25.88 USD versus 518.13 USD for premixed insulin.

Calculation of ACER can be seen in Table 2. Each of insulin regimen rank in ascending order based on its cost. Insulin aspart has the lowest ACER (1.91 USD), and premixed insulin has the highest ACER (6.34 USD). Premixed insulin was strongly dominated regimen because has increased cost and reduced effect compared with insulin detemir. The strongly dominated regimen can be excluded from analysis. Insulin detemir, insulin aspart, and the combination of insulin aspart + insulin glargine then calculated for ICER value (Table 3). The combination of insulin aspart + insulin glargine was more effective and more costly than insulin detemir, and insulin aspart results in higher ICER value compared with insulin aspart ( 0.82 and 15.01 vs. 0.18 ).

\section{DISCUSSION}

Insulin is the choice of treatment in patient with T2DM with real specific symptoms and/or increased levels of blood glucose or HbA1c [14]. Our result study suggests that treatment with insulin aspart is associated with a statistically significant reduction in FBG, PBG, and HbA1c compared with another regimen $(\mathrm{p} \leq 0.05)$, even though there is no statistically significant difference between final result value on the $3^{\text {rd }}$ month of each regimen. Insulin aspart is a bolus insulin that used to resolve the increase in glucose level after meals and maintain $2 \mathrm{~h}$ postprandial glucose level $[5,14]$. It also provides a better glycemic control which reflected in the HbA1c value [4]. The results of this study also showed that insulin aspart has an influence on changes of FBG value.

There were $57.14 \%$ of patients in insulin aspart regimen achieved the clinical effectiveness target. This result is lower when compared with the effectiveness obtained by the combination of insulin aspart + insulin glargine but was much better when compared to the result of insulin detemir. The combination of insulin aspart + insulin glargine gave the highest effectiveness as much as $58.82 \%$. Swinnen et al. defined that adding a bolus insulin to the patient with one daily dose basal insulin can improve the effectiveness of insulin regimen. Therapy with both basal and prandial insulin results in better glycemic control than basal insulin treatment alone $[15,16]$.

Total cost calculation at Table 2 showed that the usage of insulin detemir provides the lowest total cost and the highest total cost was insulin aspart + insulin glargine combination. One of the factors which influence the total cost of insulin regimen was the unit price of insulin and the amount of insulin that is used by the patient per month. Insulin detemir is a once daily basal insulin. Insulin basal is the most convenient 
insulin regimen and gave much lower cost [14,17]. The combination of insulin aspart + insulin glargine means using two types of insulin simultaneously, thus causing accumulation of total cost incurred by the patient.

CEA is a pharmacoeconomic study that compares the relative difference of cost and outcome of different treatment strategies [18]. CEA results are ACER and ICER value. Calculation of average cost ratio for each reduction of clinical outcomes and ACER demonstrated the superiority of insulin aspart compared to the three other insulin regimens. ACER was calculated by dividing the average cost of treating the patient with a regimen by average outcome per patient $[12,19]$. Although ACER was easy to calculate, they cannot be used to set priorities and decision for pharmacoeconomics consideration because ACER does not compare the costs and outcomes of between all alternatives [19]. Implementation of ACER value may use as device decision rule based on a fixed budget to maximize total effectiveness [18].

ICER described an additional cost per additional health outcome. It compares the difference between the costs and health outcome of two alternative interventions that compete for the same resources [20]. There were only three regimens that calculated for ICER value (Table 3). Premixed insulin was excluded from the analysis because of strongly dominated. Insulin aspart and the combination of insulin aspart + insulin glargine were a comparator and compared against insulin detemir. Insulin detemir was the most relevant alternative because of insulin basal was the standard intervention based on the clinical treatment guidelines $[14,20]$.

The result of ICER value can be used in decision-making for choosing regimen therapy alternatives [20]. Insulin aspart has lower ICER value compared to the combination of insulin aspart + insulin glargine. This study suggests that use of insulin aspart has an additional cost per additional health outcome less than the use of the combination of insulin aspart + insulin glargine, compared to the conventional therapy (insulin detemir). When willingness to pay is above the insulin detemir cost and its need to increase the treatment effectiveness, insulin aspart is a better option compared to the combination of insulin aspart + insulin glargine.

\section{Limitation of the study}

Limitation of this study was its small sample size and short duration. In addition, glycemic and HbA1c variability at baseline were not measured for its normality and homogenity. A long-term study with larger sample size must be carried out to evaluate a long-term clinical effect of insulin therapy. Treatment effectiveness in a long-term study can also be measured in patient quality of life. It needs to measure hypoglycemia-induced insulin as hypoglycemic episodes were most commonly reported adverse events with insulin and one of parameters that affect insulin therapy effectiveness [21]. Cardiovascular, micro- and macrovascular complication can also be measured in the long-term study. The emergence of hypoglycemic events and complications can

Table 1: Changes in insulin regimen outcomes from baseline to 3-month follow-up period

\begin{tabular}{llll}
\hline Insulin regimen & Parameters & Baseline (mean $\mathbf{S D}$ ) & 3-month follow-up (mean \pm SD) \\
\hline Insulin aspart & FBG & $251.0 \pm 62.4$ & $123.9 \pm 34.5$ \\
& PBG & $295.4 \pm 65.9$ & $185.4 \pm 54.7$ \\
& HbA1c & $11.8 \pm 2.5$ & $7.5 \pm 1.9$ \\
Insulin detemir & FBG & $252.6 \pm 72.8$ & $147.4 \pm 42.0$ \\
& PBG & $306.8 \pm 75.3$ & $218.2 \pm 51.2$ \\
& HbA1c & $12.1 \pm 2.9$ & $8.6 \pm 1.8$ \\
Premixed insulin & FBG & $146.3 \pm 40.3$ & $136.7 \pm 34.2$ \\
& PBG & $221.3 \pm 73.4$ & $216.0 \pm 58.1$ \\
Insulin aspart + & HbA1c & $7.7 \pm 2.1$ & $7.5 \pm 1.3$ \\
insulin glargine & FBG & $197.4 \pm 69.7$ & $138.2 \pm 36.7$ \\
& PBG & $296.2 \pm 66.9$ & $194.4 \pm 85.9$ \\
\hline
\end{tabular}

FBG: Fasting blood glucose is in mg/dL, PBG: Post prandial blood glucose is in $\mathrm{mg} / \mathrm{dL}$, HbA1c: Glycated haemoglobin is in $\%$, *statistically significant differences $(\mathrm{p}<0.01),{ }^{* *}$ statistically significant differences $(\mathrm{p}<0.05)$

Table 2: Total cost, average cost for unit outcome, and ACER

\begin{tabular}{|c|c|c|c|c|}
\hline \multirow[t]{2}{*}{ Parameters } & \multicolumn{4}{|l|}{ Insulin regimen } \\
\hline & Insulin detemir & Premixed insulin & Insulin aspart & Insulin aspart + insulin glargine \\
\hline Total cost* & 102.62 & 105.63 & 109.31 & 134.54 \\
\hline $\mathrm{PBG}\left(\mathrm{USD} / \mathrm{mgdl}^{-1}\right)$ & 1.52 & 19.24 & 0.99 & 1.04 \\
\hline HbA1c (USD/\% HbA1c) & 38.13 & 518.13 & 25.88 & 66.46 \\
\hline Total clinical effectiveness (\%) & 20.00 & $16.67^{* *}$ & 57.14 & 58.82 \\
\hline ACER (USD/\%) & 5.13 & 6.34 & 1.91 & 2.29 \\
\hline
\end{tabular}

${ }^{*}$ Cost is measured in IDR and converted to USD with currency 13,333.00 IDR = 1 USD, ${ }^{* *}$ premixed insulin is strongly dominated (increased cost and reduced effect), ACER: Average cost effectiveness ratio

Table 3: ICER of insulin regimen

\begin{tabular}{|c|c|c|c|}
\hline Insulin regimen & Incremental cost (USD) & $\begin{array}{l}\text { Incremental effectiveness } \\
\text { (incremental unit outcome) }\end{array}$ & $\begin{array}{l}\text { ICER (USD/incremental } \\
\text { unit outcome) }\end{array}$ \\
\hline Insulin detemir vs. insulin aspart & 6.69 & 37.14 & 0.18 \\
\hline Insulin detemir vs. insulin aspart + insulin glargine & 31.92 & 38.82 & 0.82 \\
\hline Insulin aspart vs. insulin aspart + insulin glargine & 25.23 & 1.68 & 15.01 \\
\hline
\end{tabular}

ICER: Incremental cost effectiveness ratio 
affect an amount of insulin therapy costs so that it will have an influence on the pharmacoeconomic analysis.

This study limitation can be a premise for further pharmacoeconomic study with longer study period and larger sample size. To ensure adequate cost analysis, it needs to develop a cost analysis based on health-care regulation. Pharmacoeconomic study in Indonesia needs to be developed considering of the economic burden of disease and retrieve of the National Health Insurance System has been set by the Indonesian government.

\section{CONCLUSION}

Based on ACER and ICER value, insulin aspart has an eminence in CEA compared to insulin detemir, premixed insulin, and the combination of insulin aspart + insulin glargine. We need further study to assess the long-term impact of insulin use and its economic burden on Indonesian health-care system.

\section{ACKNOWLEDGMENT}

This work was supported by Ministry of Research, Technology and Higher Education (Ristekdikti) research grant provided through institute of research and community service Udayana University.

\section{REFERENCES}

1. Mayfield JA, White RD. Insulin therapy for Type 2 diabetes: Rescue, augmentation, and replacement of beta-cell function. Am Fam Physician 2004;70:489-500.

2. American Diabetes Association. Economic costs of diabetes in the U.S. in 2012. Diabetes Care 2013;36:1033-46.

3. Hussain M, Naqvi SB, Khan MA, Rizvi M, Alam S, Abbas A, et al. Direct cost of treatment of diabetes mellitus Type 2 in Pakistan. Int J Pharm Pharm Sci 2014;6:261-4.

4. Swinnen SG, Hoekstra JB, DeVries JH. Insulin therapy for Type 2 diabetes. Diabetes Care 2009;32 Suppl 2:S253-9.

5. Petznick A. Insulin management of Type 2 diabetes mellitus. Am Fam Physician 2011;84:183-90

6. Triplitt AK, Reasner CA, Isley WL. Diabetes mellitus. In: Dipiro JT, Talbert RL, Yee GC, Matzke GR, WellsBG, Posey LM, editors. Pharmacotherapy: A Patophysiologic Approach. $7^{\text {th }}$ ed. New York: McGraw Hill; 2008.
7. Caporale JE, Pichón-Riviere A, Beratarrechea AG, Von SchulzHausmann C, Augustovski F. A Comparison of 1-year treatment costs in patients with Type 2 diabetes following initiation of insulin glargine or insulin detemir in Argentina. Value Health Reg Issues 2014;5C:14-9.

8. Helble M, Aizawa T. International Trade and Determinants of Price Differentials of Insulin Medicine. ADBI Working Paper 551. Tokyo: Asian Development Bank Institute; 2015. Available from: http:// www.adb.org/publications/international-trade-and-determinantspricedifferentials-insulin-medicine. [Last accessed on 2017 Jan 20].

9. Svensson AM, Lak V, Fard MP, Eliasson B. Total costs of basal or premixed insulin treatment in 5077 insulin-naïve Type 2 diabetes patients: Register-based observational study in clinical practice. Clin Diabetes Endocrinol 2015;1:17.

10. Phillips C. What is Cost Effectiveness?: Health Economic. $2^{\text {nd }}$ ed. Canada: Swansea University; 2009

11. Skrepnek GH. Cost Effectiveness Analysis. USA: Harvey Whitney Books Company; 2005.

12. Edejer TT, Baltussen L, Adam T, Hutubessy R, Acharya A, Evans DB, et al. WHO guide to cost-effectiveness analysis. Switzerland: World Health Organization; 2003.

13. Rudijanto A, Yuwono A, Shahab A, Manaf A, Pramono B, Lindarto D, et al. Consensus of management and prevention of diabetes mellitus Type 2 in Indonesia 2015. Jakarta, Indonesia: PB Perkeni; 2015.

14. Cefalu WT, Bakris G, Blonde L, Boulton AJ, D'Alessio D, Golden SH, et al. Standards of medical care in diabetes-2016. Diabetes Care 2016;39 Suppl 1:S52-9.

15. Holman RR, Thorne KI, Farmer AJ, Davies MJ, Keenan JF, Paul S, et al. Addition of biphasic, prandial, or basal insulin to oral therapy in Type 2 diabetes. N Engl J Med 2007;357:1716-30.

16. Holt RI. Insulin initiation in Type 2 diabetes: The implications of the 4-T study. Diabet Med 2010;27:1-3.

17. Freemantle N, Balkau B, Danchin N, Wang E, Marre M, Vespasiani G, et al. Factors influencing initial choice of insulin therapy in a large international non-interventional study of people with Type 2 diabetes. Diabetes Obes Metab 2012;14:901-9.

18. Bang H, Zhao H. Average cost-effectiveness ratio with censored data. J Biopharm Stat 2012;22:401-15.

19. Detsky AS, Naglie IG. A clinician's guide to cost-effectiveness analysis. Ann Intern Med 1990;113:147-54.

20. Lee KK, Bahri S, Talib A, Zainuddin J, Aljunid SM, Sulong S. Pharmacoeconomic Guideline for Malaysia. Malaysia: Ministry of Health Malaysia; 2012

21. Moradi M, Mousavi S. Drug use evaluation of diabetes mellitus in nonhospitalized patients. Int J Pharm PharmSci 2016;8:337-41. 